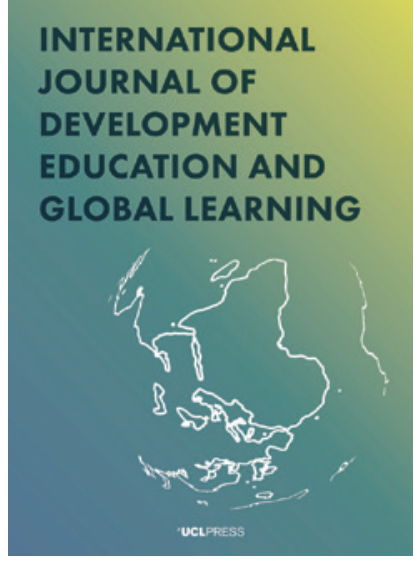

${ }^{\star}$ UCLPRESS

\title{
INTERNATIONAL JOURNAL OF DEVELOPMENT EDUCATION AND GLOBAL LEARNING
}

e-ISSN: $1756-5278$

Journal homepage:

https://www.uclpress.co.uk/pages/international-journalof-development-education-and-global-learning

\section{Engaging with the cultural 'other': The 'colonial signature' and learning from intercultural engagements}

\author{
Simon Hoult (iD
}

\section{How to cite this article}

Hoult, S. (2020) 'Engaging with the cultural "other": The "colonial signature" and learning from intercultural engagements'. International Journal of Development Education and Global Learning, 12 (2), 106-20. https://doi.org/10.14324/IJDEGL. 12.2.03

Submission date: 13 January 2020

Acceptance date: 20 July 2020

Publication date: 15 December 2020

\section{Peer review}

This article has been peer-reviewed through the journal's standard double-blind peer review, where both the reviewers and authors are anonymized during review.

\section{Copyright}

(C) 2020 Hoult. This is an open-access article distributed under the terms of the Creative Commons Attribution Licence (CC BY) 4.0 https://creativecommons.org/licenses/by/4.0/, which permits unrestricted use, distribution and reproduction in any medium, provided the original author and source are credited.

\section{Open access}

The International Journal of Development Education and Global Learning is a peer-reviewed open-access journal. 


\title{
Engaging with the cultural 'other': The 'colonial signature' and learning from intercultural engagements
}

\author{
Simon Hoult* - Queen Margaret University, Edinburgh, UK
}

\begin{abstract}
In this article, the idea of the 'colonial signature' is advanced as a potentially pivotal response to triggers that deepen or act as barriers to intercultural learning. From a postcolonial positioning, empirical data is then examined to consider the responses to intercultural-learning triggers of 14 UK-based student teachers on a study visit to India specifically through an analysis of their reflective writing and interviews.

Participants' responses to varied triggers became significant colonial signatures to their intercultural learning. The learning deepened where responses were reflexive and articulated with reference to the global powerbase that underpins study visits to the Global South. Where responses to triggers provoked more shallow comparisons with home, the colonial signatures resulted in closeddown discussion, thus acting as a barrier to further learning. This has implications not only for study visits, but also, more widely, for the approach to global learning.
\end{abstract}

Keywords: study visit, 'other', intercultural, reflexivity, colonial signature

\section{Introduction}

Study visits involving university students, often from the Global North to the Global South, have increasingly become part of the student experience in higher education since the 2010s (Jackson and Oguro, 2017). Study visits are not a neutral act and may be positioned as part of the internationalization of higher education, underpinned by neoliberal ideologies and the marketization of the sector (Harris, 2008). Their controversial nature is heightened through the firm suggestion in the literature that they result in limited changes in participants' outlook towards a cultural 'other' (Finney and Orr, 1995). This is exacerbated by limited exposure of the global powerbase during study visits on which these thoughts were constructed (Martin and Wyness, 2013; Martin and Griffiths, 2012).

Notions of hope and transformation are, however, noted in some research (Scoffham and Barnes, 2009). This became a provocation to me, as a leader of a study visit to India as part of my role in university-led Initial Teacher Education programmes, to consider whether an engagement with a cultural 'other' can provoke epistemological and even ontological change in participants (Hoult, 2017).

In this article I draw on part of my doctoral research to propose, first, the idea of the 'colonial signature' as a potentially key dimension to intercultural learning which, depending on how a learner responds, potentially aids or hinders learning. By the term 'colonial signature', I refer to the cluster of signifiers that are indicative of the cultural 'other' as a colonial project. These signifiers are underpinned by the global power 
differentials between the 'core' (the Global North) and the 'periphery' (the Global South) experienced during a study visit. The idea of the colonial signature is then considered through a critical discourse analysis of empirical research undertaken with UK-based student participants during a recent study visit to India. This research was guided by the research question 'To what extent (if at all) are responses to experiential triggers significant to participants' intercultural learning?'

\section{The study visit and its participants}

The research draws from a study visit as part of a Master's module called 'Intercultural Learning: A South India Study Visit' which was included in an Initial Teacher Education programme at a British university. The module focused on the processes of intercultural learning and personal/professional change in a global context of power inequalities. The participants and I worked together intensively for three weeks, which included three days of pre-visit preparation and 12 days in Kerala, South India, before reimmersion into their UK school placement upon their return.

Fourteen postgraduate students participated in the study visit part-way through the programme that qualified them to teach as primary and secondary school teachers. The group comprised a mix of men and women, aged 22-29, from a range of graduate disciplinary background spanning the arts, humanities and sciences. All students were self-declared white British/European and only a minority had travelled beyond Europe or North America before. This contrasted somewhat with my experience: I am in my forties and have led teacher education programmes and travelled to India many times.

In order to theoretically situate the global powerbase of the study visit's participants and hosts, postcolonial theory was introduced to the participants as part of their preparation, as suggested by Martin and Griffiths (2012). Such theory underpinned discussions of representation and stereotyping, to illustrate ways that the cultural 'other' may be positioned without drawing reflectively and reflexively on their engagement.

Through careful local negotiation the visit focused on a relatively broad range of educational institutions, including English- and Malayalam-medium schools, a teacher training college and a university. As part of their study visit each student was required to complete a journal about their experiences. The journal entries were prompted by questions that enabled participants to reflect on specific pre-visit elements of their preparation and in a more open manner during the study visit and on their return home. The journal was used as a source to reflect further upon their intercultural learning in an academic essay which formed the module assignment. Once the module was completed, I invited each student for an interview about their experiences and 12 accepted this offer. All participants agreed to their journals and essays being used as anonymized research data after the end of the module, as did all those who were interviewed. This formed the entirety of my empirical data.

\section{Our colonial signature}

I propose that our colonial signature is a personally significant response to a signifier of language, symbols, products or other images. This signature acts as a conduit or inhibiter - and, at times, both - to our intercultural learning through some two-way connection between the location of the study visit in the Global South and home in the Global North. A colonial signature is the mix of one's unique knowledge, previous 
experiences and underpinning values which provoke an individual response to these physical and metaphysical artefacts.

In recognizing the 'colonial' in colonial signature I make an inherent assumption that although, to some degree, we live in political and, to a lesser extent, economic postcolonial times, 'decolonising the mind' has yet to be largely achieved (Wa Thiong'o, 1986; Sharp, 2009). Thus, for some, this response may draw on links to a colonial era; for others, it may provide a link to globalization and the neo-colonialization of multinational corporations, for example, through the use of the English language in India or seeing a sign for a global brand. A colonial signature may be a significant means for study visit participants to relate their experiences to home. Such a connection is potentially made in the context of global power differentials between North and South, and as an influence upon the nature of the relationships made with the cultural 'other'.

The term 'signature' is used deliberately to indicate something that is personal and unique, rather than suggesting a generalized or collective experiential outcome. The colonial signature denotes writing; it suggests that we and places are written through with some form of colonialism and, therefore, it gives an insight into the ways colonialism in which is potentially written through us in the centre. The idea of the colonial signature, drawing inherently from postcolonial theory, has some resonance with Said's idea of the median category. He outlines how the median category occurs when 'something patently foreign and distant acquires, for one reason or another, a status more rather than less familiar or in other words as versions of a previously known thing' (Said, 1978: 58-9).

Said (1978: 58-9) verges on the psychoanalytical in his view of the median category as something we use:

not so much a way of receiving new information as it is a method of controlling what seems to be a threat to some established view of things ... The threat is muted, familiar values impose themselves, and in the end the mind reduces the pressure upon it by accommodating things to itself as either 'original' or 'repetitious'.

Said did not elaborate further on his theories underpinning his median category and it has been left to scholars such as Bhabha (1994) and Hook (2012) to indicate the conscious and unconscious dimensions to the median category. They both view this in terms of colonial stereotyping, which similarly resonates with the idea of the colonial signature.

Stereotyping is 'a form of knowledge and identification that vacillates between what is "in place", already known, and something that must be anxiously repeated' (Bhabha, 1994: 94-5). The seemingly stable and unstable dimensions to the generation of knowledge suggest that such thinking draws beyond our cognitive consciousness and from our unconscious who argues that without understanding the unconscious play around 'desire, anxiety and fantasy' the colonizer and the colonized will not grasp their related postcolonial dynamics of 'power and resistance' (Hook, 2012: 160). This is what Bhabha (1994) calls 'ambivalence'. He argues that the strength of ambivalence provides the currency of colonial stereotyping and enables it to be repeated so as to give an appearance of truth, but it is always over-excessive and beyond what may be proven by experience or by logical construction.

The nature of stereotyping is explored in Chimamanda Adichie's (2009) TED lecture, in which she outlines her belief that stereotypes as not necessarily wrong, but that they suffer from the representation of reality through a single story. This conflicts with Bhabha's (1994) position that a stereotype is not merely a simplification, but more 
a distorted or flawed representation of reality. Either way, the repetition of the single, partial story, if perpetuated, becomes, according to Bhabha (1994: 107), an 'arrested fixated form of representation'. Fixity is described neatly by Hook (2012: 161) as a 'buttoning down' of the 'other' such that difference is normalized through essentializing the 'other', but that it causes anxiety in the colonizer's mind.

The aim of fixity is to ensure a separation between colonizer and the colonized through an apparent purity of thinking about race or culture which is not contaminated by the 'other'. Notions of purity stem from what Bhabha (1994: 74) calls the 'myth of historical origination' where one's race or culture has primacy over others. It is easy to imagine the instability of such knowledge given the potential for counterarguments and experiences to infiltrate its apparent purity. This instability is the cause of the colonizers' anxiety and requires them to repetitively magnify difference in order for it to appear real.

The fixing of the strange onto what is more familiar is a repetitious process that 'vacillates between delight and fear' (Bhabha, 1994: 73), which links to the psychoanalytical term of 'fetish'. Fetish derives from the fear of some form of catastrophic loss that Bhabha relates to the potential for experiences to significantly challenge some people's world view. As a way to understand how stereotyping occurs, fetish helps us to see the median category, and potentially the colonial signature, as a device of fixity. A fetish may be an object, activity or experience. It occurs, according to Bhabha, through the necessity of focusing upon the construction of some form of knowledge because of a pressing need linked to a moment in history. The moments that come to our attention are a function of 'difference, defence, fixation and hierarchization' (Bhabha, 1994: 73), which thus exposes the power of the colonial within us.

The fetish is distinguished from disavowal, which is seen as a more extreme psychological defensive response to external experiences. These are seen as traumatic because they provoke 'recognition-yet-denial' (Hook, 2012: 179) of the phenomenon, resulting in no apparent change in the individual. The lack of change suggests a fixity of thinking, with other ideas pushed beyond a conscious periphery. This concurs with Andreotti's (2013) vision of a highly defended, home-based disposition towards difference where ideas are regarded as fixed, certain and resistant to challenge.

Certain values-based questions arise about who judges whether an idea is just over-simplified or a stereotype, or if it demonstrates deep understanding. Bhabha (1994) argues that in considering the process of stereotyping rather than its outcomes, we focus upon the ways in which colonial discourse is developed and maintained, which removes the temptation to test stereotyping through normalized judgements. Such judgements risk reifying stereotypes and present them as singular and whole, rather than as multiple and fragmented views that create considerable anxiety in the colonial mind (Hook, 2012). In addition, gaining understanding of the process of stereotyping, perhaps more than its outcomes, may assist in appreciating intercultural learning processes and in what ways (if at all) our colonial signatures act as barriers or as a bridge to deepen our learning.

\section{Colonial signature as reflexive opportunity}

Stereotyping should be read with regard to the 'multifarious processes of subjectivity' (Hook, 2012: 165) and it reveals significant things about the self. What we are haunted by comes to bear on the way we represent what we might begin to fixate upon and what is so disturbing that we disavow it. The process links to the idea of the colonial 
signature; however, this is not necessarily a negative process that is a barrier to learning. There is the potential for an event, or object, to become a critical turning point of learning through reflexively reviewing the reasons for its significance to our learning.

I am rather more hopeful for the colonial signature than Said, Bhabha and Hook's view of the median category, notwithstanding the potential for it to become stereotypical. Such a signature could be underpinned by fetish, fixity and anxiety, which thus dupes, provides unreliable readings and disturbs our intercultural learning. However, in a culture of reflective tentativeness where we reflexively consider the formation and significance of our signatures, they potentially become the means by which we consider the way we develop our thinking. Our signatures potentially become a milestone along the route of intercultural learning which become significant prompts to enhance our thinking through reflexivity and reflection. Our signatures potentially provide a conduit for readjusting our perceptions of self/'other' and epistemological and, perhaps, ontological change.

\section{Research methodology}

The postcolonial assumptions that underpin this work challenged me to develop research methods that complemented its attempt to challenge the orthodoxy of the centre. Following Holliday (2011: xi), I aimed to find 'alternative, more creative methods which dig beneath the surface - to find the hidden and counter-cultures of the Periphery with which to shake the Centre image'. To this end, I employed a critical ethnography approach to data collection that was infused with reflexivity. Qualitative research approaches were chosen to subjectively interpret the perceptions of intercultural learning of this small participant group. Accordingly, I resisted any temptation to generalize my findings. Rather, I used the narratives to deepen my understanding of the potential of the colonial signature as a feature of intercultural learning.

My decision to use ethnography was influenced by the inextricably entwined roles I performed as teacher and researcher, and my immersion and influence in the field which accord with the ethnographic notion of the participant-observer (Lichtman, 2006). Moreover, as the teacher I had the intention to help everyone involved in the visit, including myself, to expose epistemological assumptions. This political intention did not deliberately extend into my role as researcher; however, my mixed identity, typified through mutually supportive acts such as developing the participants' reflection through discussion, meant that my research became de facto political in its outcomes, if not its initial intentions.

Critical ethnography is explicit about the political act of research that aims to disturb our thinking. It is distinguished from more traditional forms of ethnography that 'describe what is' by asking 'what could be', indicating that critical ethnography goes beyond describing cultures and challenges the status quo (Stephens, 2009: 52). The intention of critical ethnography is to expose matters of 'oppression and inequality in society' within which is an explicit dimension of participant emancipation (Carspecken, 1996: 243). I read the exposure of hidden or 'natural' (colonial) Eurocentric assumptions as an emancipatory act, and acknowledged the potential for the research process to aid this undertaking. Accordingly, I wrote for the participants in this respect, rather than simply about their learning (Denzin, 1997), while ethically balancing my performance between the activism of the visit and the reflexivity of my research. 


\section{Data collection and analysis}

The ethnography focused upon participants' perceptions of intercultural learning performed during the entirety of their intercultural learning module. Two main forms of data were collected in order to examine the participants' learning as holistically as possible before focusing my analysis on the colonial signature for this article. First, with permission from participants and ethical clearance from the university, the students' academic written reflections and journals were analysed. These data were augmented by semi-structured interviews conducted in a place of their choosing three to four months after the module was completed, both to assist in reducing teacher-student power dynamics.

Ethnographic practice includes a wide range of interview approaches, but, when aiming to 'explore the perspectives of the people concerned', tends to be openended (Hammersley, 1998: 35). My interviews were no exception and tended towards 'conversations with a purpose' (Brewer, 2000: 67), with open and emotional engagement encouraged in the conversations. My interviews, which were recorded and transcribed, used open questions intended to elicit a conversation about intercultural learning where interviewees could develop their own ideas and themes. Although there was no schedule of pre-determined questions, we focused on three related matters: the ways in which the participants learned from the module; what they learned, including about themselves; and any lasting dimensions from the study visit that they considered remained as personal influences.

The data analysis drew on critical discourse analysis (Fairclough, 2010) of the transcripts (once they had been approved by each participant), in first seeking to identify triggers to intercultural learning and then to consider the underlying global power dynamics and ideology that underpinned them. My analysis strived to expose any rich, holistic interconnectedness between each individual's account of their intercultural learning in order to consider ideas of the colonial signature as an aspect of that learning. In the following analysis I draw on the data of all 14 participants, not in an attempt to represent the group wholly or equally, but rather to develop and deepen my understanding of the colonial signature and its potential influence on intercultural learning.

\section{Analysis and discussion: The significance of the colonial signature}

Various significant engagements with the 'other' emerged in the participants' narratives, which became colonial signatures in idiosyncratic ways. In this section I draw on four particular engagements which articulate varied responses to triggers. The first considers a brief encounter in a small town with a young woman holding a baby and begging during an early stage in the visit. The second and third come from participants' reflections on their welcome at a large, cross-phase, semi-rural school they visited, which I juxtapose with their lack of exploration of a subsequent visit to an urban international school. The fourth is drawn from the participants' overall experience of well-being during their visit.

\section{Responses to begging}

Where engagements resulted in rather uncomplicated, transcultural comparisons, the self was left reflexively unexamined and singular readings were made of the experience through limited reflection. These colonial signatures equated strongly to Said's (1978) 
median category. This is perhaps exemplified most by Becky's comparison between begging in India and in the UK. She reflected, 'Why do we feel bad when we go to India and we see the poor when we've got people living in the same deprivation in our own country and nobody cares?' (Interview). Becky's rush to draw conclusions, rather than examining the possible factors that influence our thinking, limited her opportunities for deeper learning. This perhaps kept her safe by reducing the encounter to one that was familiar from home, and a rather easy transcultural comparison ensued. The event was recognized as an early trigger by nearly half the group, but Becky's position contrasted most strongly with that of Alice, who, grappling with the incident, expressed:

a horrendous amount of guilt ... and all the rest of the journey I was just wrestling with my head thinking 'Well should I have done something?' And then I was thinking of all the stages at which ... 'How far can money go?' And 'Would money have actually helped or would money have actually been a burden?' (Interview)

Alice continued to be troubled by the same event and her inability to act, adding:

encountering this woman, [was] ... 'a powerful emotional trigger that causes conflict and dissonance' ... I wrestled with questions ... I began questioning the validity of her poverty and my ignorance as Westerner; thinking my money was the solution to her problems ... I was trying to operate in, and 'take responsibility for' a culture wherein the issue was greater than my shallow comprehension understood ... I was now questioning my Christian faith, asking where God was in her situation. (Interview)

Alice's questioning appeared to be the deepest and most sustained of the group, including considering 'Western' responses to poverty and the colonialist trap of presenting oneself as a saviour. However, she did not articulate the role of the West in the woman's poverty, instead questioning where God was. Such existential dimensions to global learning (Rogers and Tough, 1996; Scoffham and Barnes, 2009) showed a depth in the response to the situation and a willingness to articulate such matters, not through drawing on theory, but through her ontological exploration of her faith.

'Guilt' and 'ashamed' were terms used by well over half the participants to describe their feelings at various points during the study visit, often associated with the desire to 'give something back' or to 'act'. For many participants such expressions may be read colonially or neo-colonially. However, Slater was relatively less affected, having experienced significant poverty during previous travels. The majority of the responses to personal encounters with poverty perhaps reflected a donor-recipient relationship, but also a lack of agency in the few seconds this engagement lasted. Maggie, a welltravelled participant, summarized it for many, saying:

I think that was quite a hard moment for a lot of people ... Just how intense the poverty was there was quite hard to deal with ... it was our personal choice not to give her money but it was - you know that grappling decision in your head. (Interview)

The participants' desire to respond was matched by an understanding of the difficulties of achieving this in a relationship associated with economic disparity, but also in a setting where they were culturally uncomfortable and unconfident. Their reflections on the encounter with the begging woman were mostly nuanced and nobody decided 
to give her a few rupees on the spur of the moment, perhaps guided by my initial response. Alice articulated her strong feelings of guilt about what was going to happen to the woman and her baby, and articulated her perception of each participant as a 'white, rich person getting off into their truck', saying 'Don't touch me, I'm gonna go' (Interview). Such a perception was 'too uncomfortable' and Alice's:

heart was telling [me] to ... take a leap and bridge the gap but this confusion of 'What to do I'm in a culture I don't understand but what I'd do in the UK may be totally useless here or inappropriate'. (Interview)

Alice's reading of Andreotti's (2007) considerations of Spivak's contributions to education helped her to understand the wider dimensions of the violence on which the privilege of the centre is constructed and the dangers of salving one's conscience through small-scale charitable donations.

\section{On overwhelming hospitality}

The visits to schools were challenging to the participants in different ways. The rather formal welcome at the first school - a large, cross-phase, English-medium school - led by its principal and a student brass band, provoked emotional responses on which participants subsequent reflected.

Nancy was perhaps the most overtly emotionally moved participant. She reflected:

it had a greater impact on me than any other aspect of the trip and what is so important, upon reflection, is that it took me by complete surprise. Upon arrival at the school we were greeted by the school's brass band ... the moment I looked at the band I was totally overcome by emotion and for the next few hours I could not stop crying ... I think I was overwhelmed by so much of what was happening and by my mere presence in India that this was the release. Perhaps I had inflicted upon myself some kind of mental block or 'denial' phase. I believe I may have been, unknowingly, rejecting the culture. (Reflection)

Possibly it was the unspoken nature of music that took the students beyond a defensive realm of language with which, up to that point, they had guarded their emotions. After Nancy's bout of crying, which freed her from her cognitive control and cultural denial, she was able to engage with the experience both cognitively and emotionally. In short, she was able to learn more deeply.

Nancy reflected:

I believe that a large part of my emotion came from the fact that these people, people that knew nothing about us really, would put in such an extraordinary effort to make us feel welcome. In actual fact I felt like we were royalty. My crying did eventually change to what I can only really describe as pure elation. (Reflection)

The brass band welcome surprised many participants and caused them to reflect on its enormity. Maggie said:

not only was I shocked, but I was confused as to why they believed we deserved such kindness and required such high esteem. This was the first instance which made me query our colonial status within India and whether we still hold and are placed upon a superior pedestal. (Reflection) 
Using terms like 'royalty' or 'celebrity' was not restricted to Maggie; Deborah, Eve, Nancy and Jane all used similar terms to describe their welcome at this school. Maggie said later that such a welcome was 'massively overwhelming' (Interview) and similar terms were used by participants Mark and Laura to describe the event. Maggie said that the welcome at the school provoked many participants to question: 'why were they doing this for us? Why were they treating us like celebrities?' (Interview). Jane was more direct in asking: 'is it because of our nationality or the colour of our skin? Or both?' (Reflection). I resist the temptation to only consider Jane's grand-scale causational factors at play here; however, her comments were representative of many of her peers.

Before travelling, Nancy had indicated that 'our colonial heritage' is 'hugely influential to today's society' (Journal). She questioned, after the visit to the school, why so much respect was given to representatives of a country that had colonized India in the past (Journal). For many participants the shock of a brass band welcome perhaps provoked them to consider their experiences, and especially the way they were treated, in terms of the influences of Western power on the thinking and actions of some of the people they met. Upon the participants' return home and the reading and writing they did for their Reflections, they began to consider this directly in relation to postcolonial theory. Despite me raising the idea that the grand welcome was indicative of local hospitality rather than of colonial relationships, this was not countenanced by participants as the dominant factor behind such a welcome.

Jane summed up the views of others, like Mark and Becky, when she said that she thought that the 'English, as white people ... have a lot of power over there', adding that she thought that the school perceived that the group's visit brought 'status and respect' (Interview) to the school. The status that Jane referred to exposed an apparent ingrained colonial attitude in some of our Indian hosts which was experienced in both the first and many of the subsequent school visits. She summarized her surprise about this apparent colonial hegemony indicated by the nature of the receptions:

I learnt an awful lot about the colonialist mind-set that inhabit[s] us as westerners naturally, but also that there is a colonial mind-set that exists within the people I met on the trip. This is not something I was expecting. (Reflection)

\section{Signatures provoked by the unexpected}

The first school visit troubled many participants, but perhaps this early experience then informed an expectation of the reception they would receive at subsequent schools. Although this assumption was mostly borne out, their experience of visiting an international school further disrupted their thinking and their initial clarity about Indian schools. This school, catering for an economic elite, contrasted greatly with the majority of schools we visited whose pupils represented a wider cross-section of society. For many participants the shock of the familiar at the international school was considerable. They remarked upon how each classroom had poster displays, including of pupils' work, electronic projection equipment and tables and chairs in group formation. It was redolent of the UK classrooms where the participants had been recently engaged in teaching practice, although with more resources to hand.

There was no brass band to welcome the participants, and Nancy remarked it was 'very, very different' (Journal). I noted in my journal that the female principal was cordial and assertive in her welcome and that there were no (male) financial directors 
who controlled our visit, unlike in our previous experiences. It provoked Nancy to remark that after 'feeling uncomfortable' about the previous welcome, 'why did I feel that [this] school did not do enough to welcome us?' (Journal), perhaps reflecting some latent colonial legacy in conflict with her response to the brass band.

The shock that participants received at this school was considerable, yet, surprisingly, I did not note any reference to it in the participants' written reflections and only a few mentioned it, often briefly, during their interviews. Laura was one of the few to discuss the school and said that she was surprised by it and described her visit as a 'barrier [to] and a movement' in her thinking, saying that it:

stopped all the thoughts I'd started developing and then made me look at them in a different way because it was different from the first school. I had all these ideas from the first school and then those ideas were sort of cut off and then I had to sort of re-think. (Interview)

Jane was aware of the different economic strata to which the pupils of this school belonged compared to the previous settings. She said:

when we visited the School that was like a 'shocker' because there were obviously children that were from more privileged backgrounds; they didn't just really care that we were there. (Interview)

The apparent indifference of the pupils to our presence was only noticeable in comparison to the other schools we visited and I noted that pupils answered my questions well and the primary phase pupils engaged fully in an assembly that the participants and I led. The difference between the reception at this school and the others we visited is that, by and large, the school got on with its daily activities and we duly observed these. The 'celebrity' or 'royal' welcome was absent. This could have been for a number of reasons, such as familiarity with international visitors, including parents of pupils. My sense, however, was that this school did not harbour the same colonial legacy that was perhaps evident in the way that the participants were treated at the other schools that we visited. The teachers, including some European linguists, were confident about their practice and both staff and pupils were based in a highly resourced establishment with high expectations of teachers and pupils. Here, and at the university later in the visit, we were welcomed on much more equal terms.

The international school perhaps became an Indian anomaly for the participants. It was perhaps one thing to be shocked by begging or by the exuberant welcome at a school, and quite another to be confronted with a very well-resourced school with pupils from well-off backgrounds. The school's affluence did not form part of the participants' articulated preconceptions or early constructions of meaning about Kerala or its education. The school seemed remained something that was unexamined by the participants, not in terms of its workings (as these were, rightly or wrongly, compared to practice in England), but in the lack of examination by many of the participants in their response to what was apparently familiar yet in a different country. The participants who did refer to it in the interviews tended to make quick comparisons to home without using a significant critical filter. In this way, the shock of the apparently familiar became as much of a colonial signature as that of the begging woman or the brass band had been for others. The ability to make the unfamiliar strange was an emerging strength of the participants' thinking during the visit. Making the familiar strange in India, however, seemed to be much more challenging, resulting in the international school becoming an unexamined signature for many. 


\section{Well-being: A changing sense of self?}

The majority of the participants perceived their hosts to be happy, often linking this to the pleasure of an intercultural engagement between host and visitor. This was perhaps articulated most clearly by Jane who reflected: 'everyone was happy to see us and we were treated like very important people' (Reflection). Notions of happiness were often compared to home. Elizabeth referred to the many photographs she took as evidence of this, saying:

when I was out in India, I did feel - both [Deborah] and I - just looking at the pictures as well and you can see the joy, you can see the joy. And it was so nice - even though a couple of weeks later it was, 'Urgh God, England!' - but 'the joy', and you think, 'What was doing that, what was it about that?' (Interview)

The significance of meeting such apparently happy people and forming even shortterm relationships seemed to provoke a response in many participants, including Elizabeth, which became the springboard for the development of ideas of well-being. It was not only the Keralites' happiness per se that was of such significance, but also the way in which this perceived happiness seemed to aid, and even deepen, the connections with the participants.

For Becky, Maggie and Slater, the Keralite students' well-being was associated with the support they apparently received from their families. For Becky, in particular, this provoked difficult comparisons with her own 'disjointed family unit'. She wrote:

the family's level of support for the pupils to strive to do well, and become well-rounded human beings, to me was overwhelming ... with immediate reflection being made back to my own upbringing. I began to ponder the ... position I would be in now, should I have had the support of my family during my education that was so apparent here. (Reflection)

It was perhaps the enthusiastic welcome by students and their talk of supportive families that led to an uncritical universal optimism for the well-being of the children we met during the visit. Becky compared this to her own situation and that of some of her pupils in the UK and, after much soul-searching, she revealed that this given her 'some courage to make contact with the family that I had felt let down by so long ago' (Reflection). Although she was cautious, Becky's happiness and understanding of the magnitude of this re-engagement was clear in her interview.

For both Becky and Elizabeth, their perceptions of their hosts' happiness reflected their own growing explicit well-being and a changing sense of self, which underpinned many of their reflections, particularly post-visit. After Elizabeth was reimmersed in her UK school, she recognized the lesser respect afforded to her as a teacher and to her experiences (Interview). She thought reflexively about well-being and intercultural learning, writing:

my own experience of intercultural learning ... was hugely positive, improving my sense of well-being and deeply affecting my attitudes towards myself and my sense of my own progress. When I returned, I questioned my role in that outcome ... The experience also made me question the connections that could be made between intercultural learning and subjective well-being. (Reflection)

In linking well-being to intercultural learning, Elizabeth also considered ideas of plurality, openness and adaptability, writing: 
people with high levels of subjective well-being have 'an increased preference for variety' and 'a greater willingness to accept difference' (cited in Scoffham and Barnes, 2011: 540). To some extent this suggests to me that high levels of well-being enable learners to make the most of intercultural learning experiences. (Reflection)

Elizabeth revealed that ideas of well-being or happiness were not new to her and that she had previously engaged with the work on happiness of Buddhist Matthieu Ricard, after previously facing some personally difficult times. She referred to her reflexivity as 'something in the head to grow' (Interview) which seemed similar to the development of Alice's thoughts after the trigger of the begging woman. Elizabeth's realization was slow but, unlike Alice, it was not apparently a result of a singular trigger: she wrote 'I find it hard to pinpoint afterwards what it was about my intercultural experience that had made me feel so much better' (Reflection). Rather, Elizabeth's well-being, like Becky's, emerged from the whole intercultural experience. This was linked to her disposition and focus on reconsidering herself which she deemed significant in 'mov[ing] towards a fuller understanding of the learning process' (Reflection). Becky and Elizabeth's learning was similar in that it was perhaps less of a transformation and more of an intercultural provocation that caused some latent understanding of well-being and happiness to emerge. Where this learning differed was in its level of reflexivity which enabled the emergence of Elizabeth's deeper understanding of the self as well as of the significance of fluidity and plurality to deepening intercultural learning.

Elizabeth's personal development of well-being contrasted with Mark's comparison of his perceptions of the well-being of the teaching staff at his placement school with those he met in Kerala. Mark returned to school to be met by the pressures of accountability in the English education system which had resulted in a local authority review of teaching at his school following a critical inspection. He regarded the unhappiness and stress of staff there to be the opposite of his perceptions of the teachers he met in Kerala (Reflection).

Mark's transcultural comparison of well-being, however, lacked the reflexive exploration of Elizabeth's thinking. This was perhaps, counterintuitively, linked to his apparently open, non-judgemental engagement in intercultural settings. He explained to me this cognitive approach resulted from his degree where he was taught to express opinions only if he could support them. As Kerala was new to Mark, he considered that he did not have the weight to support assertions and so he would not express an opinion about them (Interview). I found a similar lack of reflexive depth in Holly's statements about her learning. She described a careful process by which she 'stepped back' from an experience, saying that trying to forget her preconceptions and approaching experiences with a 'blank canvas' helped her to learn: when she was 'in the "there and the now" everything was forgotten' (Interview).

Holly and Mark's approaches possibly masked certain assumptions that consequently remained unchallenged and inhibited the depth of their learning, whereas others explored their learning theoretically and searched for agency. Fay perhaps expressed the most open approach to intercultural learning, reflecting that she 'actively work[ed] away from [her] preconceptions of the culture' while also resisting representing Kerala with a single story (Reflection). She was also aware that her learning would potentially be enhanced by developing a fluid positioning in terms of her learning and self; referring to Andreotti (2010) she wrote:

if we can recognise 'knowledge, learning, reality and identities as socially constructed, fluid, open to negotiation and always provisional' 
(Andreotti, 2010: 6) then we allow our identity and understanding to be reconstructed by transformational experiences. (Reflection)

Fay's approach to learning has some resonance with Elizabeth's. Such a fluid approach to learning deepened intercultural learning by avoiding fixed and singular views of Kerala or its education. I am left, however, with the thought that no participant seemed to question the nature of the perceived well-being of their hosts, which seemed to be regarded as universally good - almost in a rose-tinted, Orientalist manner. Wellbeing thus became a bridge to deepening intercultural learning for participants such as Elizabeth, while simultaneously acting as a barrier to deeper learning about wellbeing by all.

\section{Discussion}

Important pivotal moments from intercultural engagements were evident in the vast majority of the participants' narratives. Through their responses, these became colonial signatures but, significantly, in idiosyncratic ways. Some of the engagements were singular occurrences and high in emotional, and, for some, existential, magnitude. This is exemplified powerfully in Alice's response to begging and Nancy's response to the brass band. Others were more frequent and a lower order of magnitude, but still of personal significance, such as Becky and Elizabeth's consideration of well-being. Where engagements resulted in rather uncomplicated, transcultural comparisons they became simplistic colonial signatures. In such cases, the self was left reflexively unexamined and singular readings were made of the experience through limited reflection. These signatures equated strongly to Said's (1978) median category, perhaps exemplified most by Becky's comparison between begging in India and the UK which illustrated how reaching quick conclusions, rather than dwelling on the possible assumptions that underpin our thinking, limit opportunities for deeper intercultural learning.

Depth of reflection seems to be highly significant to the nature of a colonial signature. An unexamined engagement, such as the participants' almost universal lack of consideration of the international school and subsequent disavowal, was still a noteworthy signature, as too was the lack of a critical response to our hosts' wellbeing. These signatures became barriers to learning rather than something that could potentially transport the learner to deeper understandings of place or people. The lack of a reflexive consideration of the self, or a universal understanding of the 'other', also seemed to be a barrier to deeper learning, notwithstanding some personally powerful outcomes such as Becky's reconnection with her family.

It was the reflexive dimension within the colonial signature that enabled some apparently pivotal, personal experiences to provoke changes in world views. It happened at the scale of the self, but in relation to the 'other'. The deepest reflexive responses to triggers were associated with the colonial signatures of those who could simultaneously hold uncertainty and conflicting ideas from an engagement, such as Alice, when dealing with what was, for many, an emotionally, or even existentially, challenging event. The most reflexive signatures were characterized by an understanding of the self and the 'other' within the context of global power inequalities and by a flexibility in thought and avoidance of a 'single story' of the 'other' in response to intercultural engagements.

In relation to theory, power and colonial underpinnings to the engagements began to be deconstructed, enabling assumptions about the 'other' as well as the self to be exposed. Fundamentally, reflexive responses to these triggers led to a potential 
reconsideration of self, and where a language was accessed through some form of theoretical or philosophical underpinning, it enabled deeper learning to occur, such as Alice's faith or Elizabeth's well-being.

Inherent in the colonial signatures was a tension between the immediate experience and an emergent and transitional participant understanding of their situated learning within an awareness of global power dynamics. The significance of pedagogy to support this is not the focus of this article, but it should not be ignored, and has been explored elsewhere (Hoult, 2017). It was important that participants could express their feelings and thoughts. Alice expressed this through her faith, but the growth of most participants' awareness was often aided by postcolonial theory. The limitations of postcolonial theory were evident in the difficulties in linking the cognitive/theoretical and emotional and/or existential responses to an experience and in gaining agency through such a deconstructive theory. It is possible that colonial signatures developed within a simultaneous Orientalist approach to an immediate engagement with the 'other', while beginning to reform perceptions of home and to recognize the postcolonial dimensions, or at least the unequal power dynamics, within such engagement.

This exploration of intercultural learning provoked by triggers during a short study visit is made in the context of research that shows that study visits often do not expose epistemological assumptions or the inherent power dynamics that underpin a study visit from the Global North to the Global South. This investigation of participants' colonial signatures through participants' reflection and reflexivity has shown that such power dynamics can be explored so as to expose participants' epistemological assumptions that underpin their world views. Such study visits not only resist charges that they exist to enhance the neoliberal metric of the student experience, but challenge dominant 'natural' discourses of the Global North through a meaningful and deep cultural engagement with the 'other'.

The colonial signature, notwithstanding its influence on study visit learning, is perhaps significant to global learning more broadly, especially in a time of a global pandemic that will severely restrict study abroad. Avoiding closed, singular readings of the 'other' and instead using global learning to develop reflexive considerations of the self, through which we challenge Eurocentric world views, seems a powerful objective for global learning. In addition to longitudinal studies of study visits, a focus on the reflexive self in the global learning classroom seem to be clear future directions for research.

\section{Notes on the contributor}

Simon Hoult is Senior Lecturer at Queen Margaret University, Edinburgh, where he leads on teacher education programmes. In addition, he has taught on a range of Master's and doctoral programmes, primarily focusing on intercultural and international education.

\section{References}

Adichie, C. (2009) 'The danger of a single story'. TED Lecture, July. Online. http://www.ted.com/ talks/chimamanda_adichie_the_danger_of_a_single_story.html (accessed 17 August 2020).

Andreotti, V. (2007) 'An ethical engagement with the Other: Spivak's ideas on education'. Critical Literacy: Theories and Practices, 1 (1), 69-79.

Andreotti, V. (2013) 'Taking minds to other places'. Primary Geographer, Spring, 12-13.

Bhabha, H.K. (1994) The Location of Culture. Abingdon: Routledge. 
Brewer, J. (2000) Ethnography. Buckingham: Open University Press.

Carspecken, P. (1996) Critical Ethnography. A theoretical and practical guide. New York: Routledge.

Denzin, N. (1997) Interpretive Ethnography: Ethnographic practices for the 21st century. Thousand Oaks, CA: SAGE Publications.

Fairclough, N. (2010) Critical Discourse Analysis: The critical study of language. 2nd ed. Abingdon: Routledge.

Finney, S. and Orr, J. (1995). "'I've really learned a lot, but ...": Cross-cultural understanding and teacher education in a racist society'. Journal of Teacher Education, 46 (5), 327-33. Online. https://doi.org/10.1177/0022487195046005002.

Hammersley, M. (1998) Reading Ethnographic Research. 2nd ed. London: Longman.

Harris, S. (2008) 'Internationalising the university'. Educational Philosophy and Theory: Incorporating ACCESS, 40 (2), 346-57. Online. https://doi.org/10.1111/j.1469-5812.2007.00336.x.

Holliday, A. (2011) Intercultural Communication and Ideology. London: SAGE Publications.

Hook, D. (2012) A Critical Psychology of the Postcolonial: The mind of apartheid. London: Psychology Press.

Hoult, S. (2017) 'Aspiring to a postcolonial pedagogy through engagement with the Other: Deepening intercultural learning from a South Indian study visit'. In Jackson, J. and Oguro, S. (eds), Intercultural Interventions in Study Abroad. Abingdon: Routledge.

Jackson, J. and Oguro, S. (eds) (2017) Intercultural Interventions in Study Abroad. Abingdon: Routledge.

Lichtman, M. (2006) All You Need to Know about Qualitative Research. Thousand Oaks, CA: SAGE Publications.

Martin, F. and Griffiths, H. (2012) 'Power and representation: A postcolonial reading of global partnerships and teacher development through North-South study visits'. British Educational Research Journal, 38 (6), 907-27. Online. https://doi.org/10.1080/01411926.2011.600438.

Martin, F. and Wyness, L. (2013) 'Global partnerships as sites for mutual learning'. Policy and Practice: A Development Education Review, 16, 13-40.

Rogers, M. and Tough, A. (1996) 'Facing the future is not for wimps'. Futures, 28, 491-96. Online. https://doi.org/10.1016/0016-3287(96)00021-3.

Said, E. (1978) Orientalism. London: Penguin Books.

Scoffham, S. and Barnes, J. (2009) 'Transformational experiences and deep learning: The impact of an intercultural study visit to India on UK initial teacher education students'. Journal of Education for Teaching: International Research and Pedagogy, 35 (3), 257-70. Online. https://doi.org/10.1080/02607470903091294.

Sharp, J. (2009) Geographies of Postcolonialism. London: SAGE Publications.

Stephens, D. (2009) Qualitative Research in International Settings: A practical guide. Abingdon: Routledge.

Wa Thiong'o, N. (1986) Decolonising the Mind: The politics of language in African literature. Oxford: James Curry. 